\title{
Testing Fairness Principles for Public Environmental Infrastructure Decisions
}

\author{
Sara Schmid ${ }^{1} \cdot$ Rudolf Vetschera $^{2} \cdot$ Judit Lienert $^{1}$ (iD
}

Accepted: 21 January 2021 / Published online: 15 February 2021

(C) The Author(s) 2021

\begin{abstract}
Public infrastructure decisions affect many stakeholders with various benefits and costs. For public decisions, it is crucial that decision-making processes and outcomes are fair. Fairness concepts have rarely been explored in public infrastructure planning. We close this gap for a global issue of growing importance: replacing sewer-based, centralized by decentralized wastewater systems. We empirically study fairness principles in this policy-relevant context, and identify possible influencing factors in a representative online survey of 472 Swiss German residents. In a transition phase, innovative, decentralized pilot wastewater systems are installed in households. We designed two vignettes for this context to test the adhesion to principles of distributive justice-equality, equity, and need—at individual and community levels. A third vignette tests procedural justice with increasing fulfilment of fair process criteria. The results confirm our hypotheses: equity is perceived as fairer than equality at individual and collective levels. Contrary to expectations and literature, need is perceived as even fairer than equity. Procedural justice results confirm literature, e.g., the majority (92\%) of respondents deems a policy fair that includes them in decision-making. Only few demographic and explanatory factors are significantly correlated with respondents' fairness perceptions. Although unexpected, this is positive, implying that introducing decentralized wastewater technology can be designed for the entire population independent of characteristics of individuals. Generally, our results confirm literature: fairness perceptions depend on the circumstances. Hence, they should be elicited in the exact application context to be able to enter negotiation processes and provide concrete advice to decision makers.
\end{abstract}

Keywords Distributive justice · Environmental policy · Influence factors · Population survey $\cdot$ Procedural justice $\cdot$ Public infrastructure

Judit Lienert

judit.lienert@eawag.ch

Extended author information available on the last page of the article 


\section{Introduction}

Public infrastructure systems provide many benefits to citizens and society, but also cause monetary and other costs. Since decisions about such systems inevitably involve the interests of various stakeholders, concerns of fairness become crucial. The literature discusses many concepts of fairness and justice (Konow 2003). In a democratic society, support from the general public is essential for implementing decisions. This also applies to decisions about public infrastructure, which will be accepted if they reflect those fairness concepts the public considers as appropriate. However, research on fairness concepts in public infrastructure planning is scarce (Kervinio 2016; Neal et al. 2014). Our study aims at closing this gap by conducting an online survey among a representative sample of citizens in Switzerland.

We study fairness in the context of a current problem in wastewater systems: existing centralized sewer-based systems are ageing, may be inefficient, and are increasingly criticized for being unsustainable (Larsen et al. 2016). They could be replaced by innovative, decentralized systems. Decentralized systems sometimes require users to accept inconveniences and additional maintenance responsibilities, which could be reflected in reduced fees or direct subsidies. This paradigm change in urban water management (Larsen et al. 2009) is a complex collective decision, which requires a broad consensus among citizens, and in which fairness is a major concern.

The remainder of this paper is structured as follows: In section two, we give a brief overview of the application context of wastewater management and of fairness concepts in the literature. Section three describes our online survey and introduces the research hypotheses. In section four, we present results of the survey, and discuss them in section five. Section six ends with conclusions and recommendations.

\section{Background and Literature Review}

\subsection{Urban Wastewater Management and Public Decision-Making in Switzerland}

The prevailing system to dispose of wastewater is a sewer network, connecting settlements to a treatment plant. These wastewater infrastructures are ageing; their rehabilitation will require massive investments (Larsen et al. 2016; OECD 2015). Their sustainability and limited flexibility to adapt to climate or population changes are increasingly questioned in literature (Eggimann et al. 2015; Farrelly and Brown 2011; Gleick 2003; Larsen et al. 2016; Libralato et al. 2012). Alternative, decentralized wastewater treatment systems are already in use worldwide (Larsen et al. 2013; Singh et al. 2015) and are seen as a promising alternative (Hoffmann et al. 2020). They can achieve similar or even better environmental standards as centralized systems (Harris-Lovett et al. 2015; McConville et al. 
2014), but require adaptions and effort such as maintenance or space in the cellar from users. The most advanced systems are still in the pilot testing stage and require openness to experimentation (Lienert and Larsen 2007, 2010).

This transition is not only a technical, but also a political problem (Hoffmann et al. 2020; Larsen et al. 2016). The prevailing wastewater system is a communally financed and organized infrastructure, while decentralized wastewater systems could be considered as privately owned and managed household devices. Pilot testing of innovative systems in a practical environment will put additional burdens on initial users, who face uncertainty about how the system actually works.

This transition therefore might increase inequality among users. In a democratic society, such a major transition requires the consent of affected citizens. This is particularly the case in Switzerland, which has an elaborate system of citizen participation. Decisions about community investments and any larger system changes, require a majority vote by the communal population. Innovative propositions will never make it to an implementation stage if they have not been previously discussed and carefully prepared. In such a setting, it is thus crucial to understand precisely the criteria by which citizens evaluate such proposals. Experience in related fields has shown that hostility and resistance to innovations can also be large in the water sector, e.g., concerning general water reforms (Lukasiewicz et al. 2013), or a potable wastewater reuse scheme (Hurlimann and Dolnicar 2010). In our view, understanding and acknowledging the interests of concerned citizens is necessary to prevent opposition against innovative projects.

Previous research in wastewater infrastructure indicates that stakeholders consider "a fair distribution of burdens and costs" important for an acceptable decision process (Haag et al. 2019). However, it is quite unclear how they interpret "fair". Notions of fairness might depend on the specific context (Miller 1992). The present study was conducted in the context of a decision-support process for Swiss rural communities concerning their future wastewater management systems (Beutler et al. 2020). This allows us to study fairness perceptions in a realistic setting, and to provide some guidance to policy makers on how to design the actual implementation.

\subsection{Fairness Concepts in the Literature}

Many scientific disciplines discuss concepts of fairness of allocations of costs and benefits. Even in economics, which traditionally has focused on efficiency, concerns of fairness have found increasing attention in empirical studies (Fehr and Schmidt 1999). Differentiated concepts of fairness evolved in sociology and political science, which distinguish between the concepts of distributive and procedural justice. For conciseness, we introduce these concepts only briefly and refer to literature (e.g., Konow 2003) for more details.

Distributive justice evaluates the allocation resulting from some decision process, while procedural justice considers properties of the process itself (Colquitt 2001; Cook and Hegtvedt 1983; Konow 2003; Thibaut and Walker 1978). A fair process (e.g., an unbiased random mechanism) might still lead to an unbalanced distribution, and an inherently unfair process to a fair distribution. Literature defines several 
criteria of distributive justice. According to the criterion of equality (Cook and Hegtvedt 1983; Welsh 2004) or egalitarism (Cappelen et al. 2007; Konow 2003), a distribution is fair if every actor receives exactly the same outcome. The concept of equity considers a distribution to be fair if it reflects contributions of actors. Typically, this is interpreted that the ratio of benefits should reflect the ratio of contributions. However, weaker variants consider only rank orders (Cook and Hegtvedt 1983), i.e., the actor who contributes most should also receive most. According to the concept of need, a distribution is fair if it fulfills the needs of recipients.

Our goal is not to identify the most appropriate fairness concept in our context from a normative perspective, but to find out which fairness concepts the actual stakeholders find most appropriate when allocating the costs and benefits of switching to a decentralized wastewater system. Without going deeply into the discussion on the relationship between normative and empirical research on concepts of justice in literature (e.g., Gaertner and Schokkaert 2012; Miller 1992), we note that this literature has identified two major approaches to empirical studies on fairness. Empirical research can on the one hand be seen as normative, in that a legitimate democratic decision should be grounded in the fairness concepts shared by the citizens. On the other hand, from a more pragmatic perspective, understanding citizens' notions of fairness is a prerequisite for implementing measures that have allocative consequences, since it reduces possible resistance against such measures. In accordance with a considerable part of the empirical literature, we follow the pragmatic perspective.

There are many empirical studies analyzing the fairness concepts which relevant stakeholders deem appropriate in various contexts. For instance, when allocating resources to sports teams, equality and need principles were considered as fairer than equity (Mahony et al. 2010). In contrast, the equity principle is often preferred in the context of job design (Romaine and Schmidt 2009). For the allocation of student grants (Steiner et al. 2006), respondents tended to follow the need principle. The context and type of resource such as material and immaterial benefits (Otto et al. 2011) thus influence which fairness criterion is deemed appropriate (Conlon et al. 2004).

Management research developed the concept of organizational justice (Cropanzano and Molina 2015; Whitman et al. 2012) and has identified several effects of perceived justice influencing the behavior of members of an organization. The fairness criteria used by organizational members depend on various factors such as national culture (Jungeilges and Theisen 2008; Miller 1992), or whether justice is evaluated by subordinates (affected by a decision) or superiors (making a decision; Cohn et al. 2000; Heuer et al. 2007).

Other empirical studies compared fairness principles in public policy settings similar to our topic. Reeskens and van Oorschot (2013) found considerable differences between topics (old age pensions and unemployment benefits) and countries. For instance, equality was preferred for unemployment benefits, while preferences were less clear-cut concerning old-age pensions. Some effects were caused by individual characteristics, e.g., less well-off persons more strongly preferred the need principle. Similar differences according to income were also noted in the studies surveyed by Miller (1992). Concerning the expansion of a nuclear plant, both 
distributive and procedural justice were related to accepting the decision-making process (Besley 2010). Furthermore, acceptable siting rules promoted the willingness of hosting a nuclear waste repository (Frey and Oberholzer-Gee 1996). These rules included negotiations between the federal government and prospective host communities until one voluntarily accepts to site a repository, inclusion of foreign experts, a lottery, and two price mechanism procedures. For childcare, equality was consistently preferred for allocating services, but higher income increased the preference for equity (Eek et al. 1998). Concerning water allocation in Australia, economic considerations seem to have some importance for the population, but more important were local justice issues and stakeholder involvement (Lukasiewicz et al. 2013; Syme et al. 1999). All these studies provide clear evidence that, depending on the context, different principles are considered as fair. Empirical research that presented different problems to the same set of respondents also found that the same person might consider different approaches as fair in different contexts (Herrero et al. 2010).

Perceptions of fairness depend not only on problem characteristics, but also on individual factors such as gender (Miller and Ubeda 2012; Romaine and Schmidt 2009), social status and age (Bellemare et al. 2011), social dominance orientation (Pratto et al. 1999), religious orientation, and political preferences (Reeskens and van Oorschot 2013). Other studies also considered collective variables such as organizational (Mannix et al. 1995) or national culture (Gao 2009; Isaksson and Lindskog 2009; Otto et al. 2011), or the size of the city in which one lives (Eek et al. 1998).

Literature on organizational justice also distinguishes between justice concepts at the individual level (e.g., remuneration paid to individual workers), and at the group level (e.g., benefits allocated to entire teams; Li and Cropanzano 2009; Mossholder et al. 1998). We consider this distinction to be particularly relevant for our research, since the transition to a decentralized system shifts costs (both monetary and in terms of effort) from communities to individual households. Still, political decisions at a higher level frequently allocate resources to entire communities. Existing literature has found that different fairness principles might be considered appropriate at the level of individuals and the level of organizational units (Clayton 2000; Hegtvedt 2005), and also between small groups and society at large (Miller 1992).

Existing literature considers fairness at these levels in isolation, but does not consider the consequences of decisions at the group level for individuals. This focus is appropriate for e.g., small teams, which can easily develop a shared identity. However, even in small villages, individual households might act differently, and be affected differently by decisions concerning the entire community. Consider for example an allocation of resources according to the principle of equity at the level of communities, i.e., a preferential treatment of communities that contribute significantly as an aggregate. The fact that a community as a whole makes a contribution, e.g., by serving as a test site for innovative wastewater systems, does not imply that all members of that community contributed.

This tension between actions taken at the individual level and rewards at the collective level could influence the perception of fairness for several reasons. On the one hand, there is an incentive perspective. Providing incentives for individual 
efforts at a collective level dilutes incentive effects because it allows for some members to free-ride on the efforts of others. Thus, the potential benefit of the equity principle in providing incentives for effort decreases when considering entire communities, although it does not vanish entirely. On the other hand, the allocation of benefits to communities could be seen as a question of providing rewards ex post. If the allocation mechanism is not yet known when households decide about participation, the choice of an allocation mechanism has no (direct) incentive effects (ignoring the possibility that there are expectations about how the allocation mechanism will work). However, an outside observer judging the fairness of different allocation mechanisms still will be able to note that some households might benefit from the reward even though they had not contributed effort. This would also lead to the equity principle being judged as less fair when applied to communities in comparison to its application to individual households, when only those who actually contribute receive a reward.

In contrast to the literature on organizational justice, our main concern here is not how entire communities develop a joint notion of fairness, but which fairness criteria are considered appropriate by outside observers when decisions (allocations) involve entire communities. Although this question has not yet been addressed in literature, we consider it an important exploratory contribution. Our study thus aims to make two contributions: To study which fairness principles actual stakeholders consider appropriate in the specific context of wastewater management, thereby contributing to the management of change processes in this domain, and to study factors that influence these perceptions, in particular the so far rarely researched distinction between allocations at the individual and collective levels.

\subsection{Aims, Hypotheses, and Research Questions}

We address both distributive and procedural justice. For distributive justice, we focus on the concepts of equity, equality, and need. In the literature, equity is considered the fairest approach (Konow 2003; Schokkaert and Overlaet 1989), particularly when allocating monetary rewards (Barber and English 2018), and in a context of economic productivity (Deutsch 1975). We hypothesize that in general, equity will be rated the most appropriate fairness criterion. This rating can be moderated by the level at which costs and benefits are allocated. As explained before, several factors might make the equity principle less attractive when applied to communities rather than individuals, leading to a shift of preferences towards equality at the community level. Our hypotheses about procedural justice focus on specific properties of the process. We also analyze whether personal characteristics influence the rating of fairness criteria.

Thus, our overarching research questions are:

RQ1 How do subjects rate the distributive fairness criteria equity, equality, and need, when benefits are allocated to, and contributions are made by, individuals? To what extent does this rating depend on individual characteristics of respondents? 
RQ2 How do subjects rate the distributive fairness criteria equity and equality if benefits and contributions relate to communities rather than individuals? To what extent does this rating depend on respondents' individual characteristics?

Note that in RQ2, we do not refer to the concept of need, since it might be more difficult to specify needs of entire groups.

RQ3 How do subjects rate the criteria of procedural fairness (such as impartiality, objectivity, or transparency), and to what extent does this rating depend on respondents' individual characteristics?

We elaborate these general questions for our specific context in Sect. 3.4.

\section{Method}

\subsection{Online Survey}

We performed a pre-test with twelve Eawag ${ }^{1}$ researchers (wastewater engineers) in spring 2018. Based on their feedback, we shortened the questionnaire and added more illustrations. We carried out a second pre-test in June 2018 among 154 undergraduate students of an introductory lecture in business administration at the University of Vienna ${ }^{2}$, of whom 29 completed the survey. As an incentive, ten randomly drawn respondents received an Amazon voucher of $€ 25$. Most respondents perceived the questionnaire as interesting and informative. We thus made only small adaptations in wording and layout.

Participants for the final online survey were recruited via e-mail by a market research company Respondi (2018) from a panel of 20,000 potential respondents. The sample was representative of the Swiss German population regarding gender, age distribution, and size of town. An English translation of the survey is provided in the Supplementary Information, SI-1.

\subsection{Response Rates and Demographics}

The link to the online questionnaire was sent to 3444 panel members between June and July 2018. The total response rate after three weeks was $33.5 \%$ (=1153 respondents). 600 questionnaires were completed, 553 participants did not finish the survey because we excluded them by quota, or they abandoned the survey. We excluded 128 cases because of unreliable data, e.g., random answers in textboxes, obviously clicking through ratings (same ratings throughout), or being twice as fast as average, resulting in 472 usable observations.

\footnotetext{
1 Swiss Federal Institute of Aquatic Science and Technology, www.eawag.ch.

${ }^{2}$ https://ufind.univie.ac.at/de/course.html?lv=040058semester $=2018 \mathrm{~S}$
} 


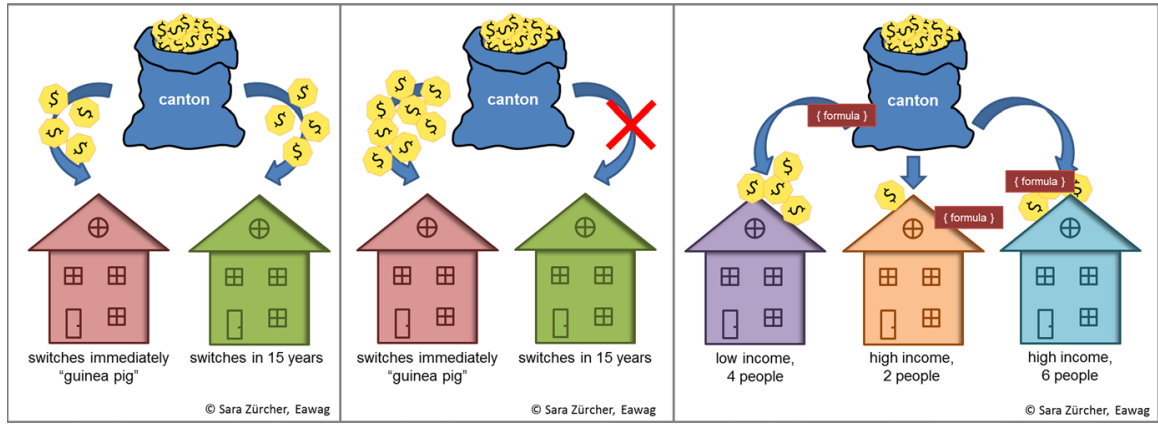

Fig. 1 Illustration of vignettes (distributive justice at the individual level)

We used two questions to check whether the respondents had read our information (Sect. 3.3). Fifty-three participants answered both questions wrongly, 135 answered one correctly, and 284 answered both correctly. We compared all fairness ratings of these three groups. Because there were only sporadic differences, we included the whole sample $(\mathrm{N}=472)$ in most analyses (exception see 4.3).

The final sample is representative for the German speaking population in Switzerland, it deviates at most $2.2 \%$ from the population average in all relevant dimensions (details in Supplementary Information, SI-4).

\subsection{Questionnaire}

The first part of the questionnaire requested demographic information, and then introduced the fictitious village of Angarten, used in the following vignettes, followed by the two questions. The main part of the survey contained three vignettes that addressed different fairness concepts. The first vignette described different mechanisms to allocate funding to households who switch earlier or later to a decentralized wastewater system. Concepts of fairness were represented by allocating funding equally to all households (equality), only to households participating in the pilot phase (equity), and according to a formula that considers the situation of each household (need). The second vignette addressed the collective level. It described two villages, who participate-or not-in a pilot program, and then receive additional funding for the final conversion to a decentralized system. Equality was represented by distributing the funding equally to both villages; equity by allocating it only to the participating village. Additionally, participants could indicate the allocation they considered fair. The last vignette referred to procedural justice and described different approaches to select households to test decentralized systems: selection by Gut feeling (no element of procedural fairness), by Chance (unbiased), according to Criteria (transparent process treating participants with respect), and Voluntary participation (having a voice). Participants rated the fairness of different approaches in each vignette on a six-point Likert scale ranging from "Totally fair" (German: "Völlig fair") to "Totally unfair" (German: "Überhaupt nicht fair"). 
All vignettes were described in text and illustrated with graphics (see example in Fig. 1). To avoid biased answers, we described each fairness concept by a picture of similar style and roughly the same number of words (Schuwirth et al. 2012).

The fourth part of the questionnaire elicited additional variables such as to what extent respondents considered it important that "people are rewarded for their effort", or religiousness and political orientation. Finally, a small quiz of four questions tested the participants' knowledge of wastewater systems.

\subsection{Hypotheses and Research Questions}

From the general research questions (Sect. 2), we derived specific hypotheses (whenever literature allowed a clear prediction) or research questions for the context of our vignettes (Table 1). Research question RQ1 referred to distributive justice at the individual level. Households who immediately switch to a new technology make a contribution. In accordance with literature (Konow 2003; Schokkaert and Overlaet 1989), we hypothesized that equity would be rated as the fairest concept (H1.1 and H1.2). Since there are no strong theoretical arguments for comparing equality vs. need, we formulated this as a research question (RQ1.3). We analyzed the impact of individual characteristics in RQ1.4. Literature associates religiousness with altruistic behavior (Ahmed and Salas 2011; Jiang et al. 2015; Koenig et al. 2007), but also shows that religious children exhibited less altruism and more punitive tendencies (Decety et al. 2015). Because of this ambiguity, we formulate an open research question, and furthermore include social commitment in RQ1.4.

RQ2 refers to the collective level. Since this vignette involved only two villages, we also asked respondents to specify the allocation of benefits they consider as fairest. Based on the above arguments (Konow 2003; Schokkaert and Overlaet 1989), we expected a preference for equity $(\mathrm{H} 2.1)$, and therefore an allocation of more than $50 \%$ to the contributing village (H2.2). However, compared to the first vignette, we expect an increase in the rating of equality (H2.3). We also analyzed the impact of individual characteristics at the collective level (RQ2.4) and on the shift in ratings (RQ2.5).

The four approaches in the third vignette fulfill an increasing number of criteria of a fair process (Bies 1987; Leventhal et al. 1980; Thibaut and Walker 1978; Tyler 1989). We hypothesized that subjects would rate the approaches "Voluntary" > "Criteria" > "Chance" > "Gut feeling" (H3.1). Differences in the fairness ratings of the vignettes therefore represent the impact of criteria of procedural fairness. We also analyzed the impact of individual characteristics on the rating of procedural justice criteria (RQ3.2).

\subsection{Data Analysis}

All data were analyzed with R (R Core Team 2017). For normally distributed data, we computed paired t-tests, otherwise paired Wilcoxon tests. We adjusted p-values with the Bonferroni method (Field et al. 2012). 


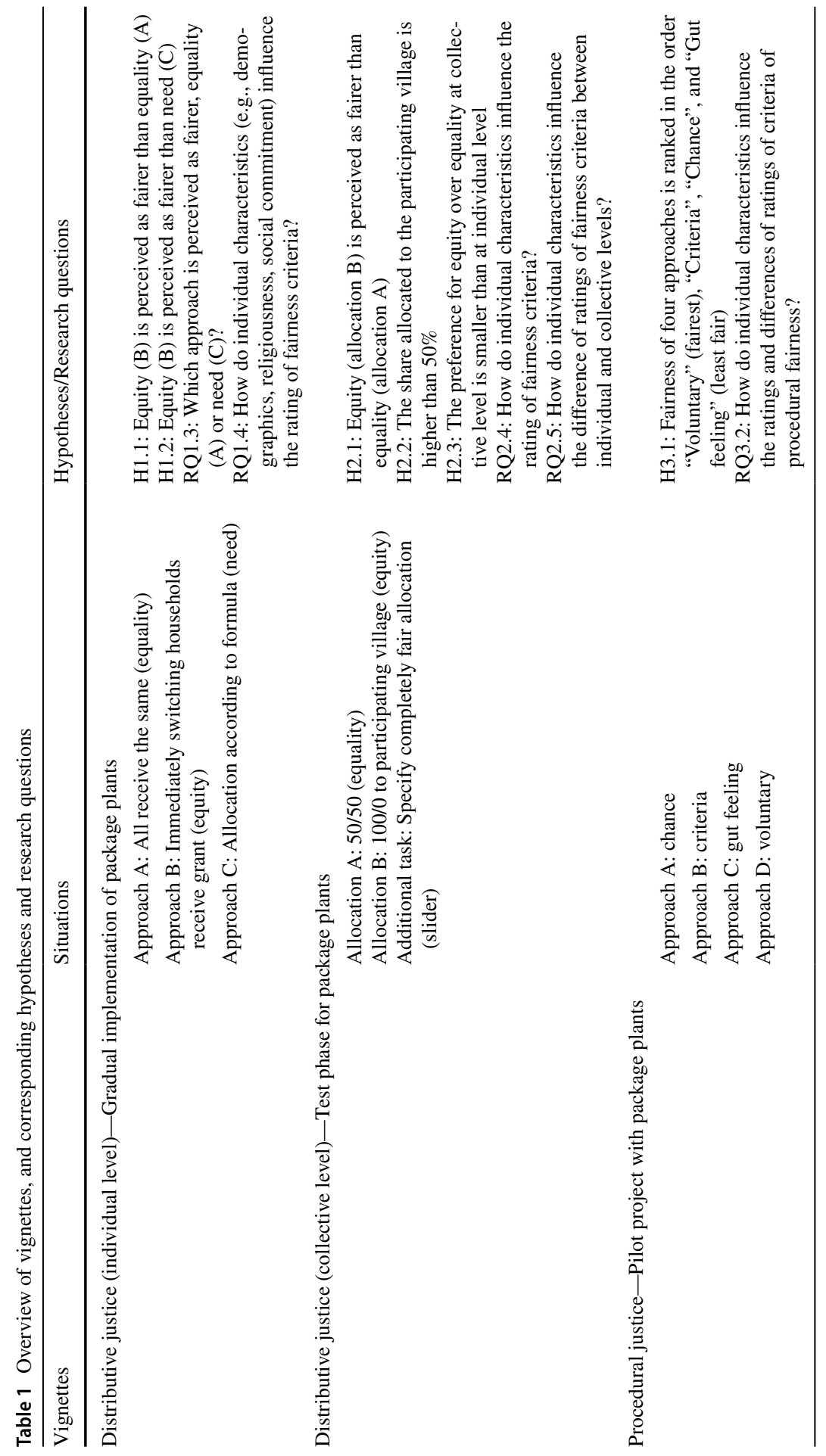


To analyze the impact of individual characteristics on differences between approaches, we used differences of ratings as dependent variables in a regression analysis. Thus, a possible subject effect in the two evaluations cancels out and we can use a standard OLS regression (Ordinary Least Squares) rather than multi-level models. For models in which standardized residuals were normally distributed, we report results of the OLS regression model. Otherwise, we report the bootstrapped results (10,000 bootstrap samples).

To analyze possible differences between non-religious and religious respondents (RQ4.2), we split the sample at the median and applied a Wilcoxon rank sum test. We used a similar split for social commitment (RQ4.3).

\subsection{Outliers}

To identify univariate outliers, we considered z-scores of all numeric variables larger than 3.29 as outliers (Tabachnick and Fidell 2007). We found outliers only in the duration of the survey. These were not further investigated, since we had already excluded the fastest participants. An analysis of the standardized residuals and the covariance ratios indicated several multivariate outliers in each model. We used Cook's distance to judge their influence on the models. Since it was never larger than the critical value of 1 (Cook and Weisberg 1982), we did not remove them.

\section{Results}

\subsection{Perceived Fairness of the Current Situation}

Table 2 summarizes the distributions of fairness ratings for all approaches. Participants seemed to have a neutral opinion about the fairness of the current situation, $64.8 \%$ fall in the two middle classes. The mean value of 3.89 provides a benchmark, to which we can compare the other ratings. More detailed analyses and results are given in the Supplementary Information (SI-6 - SI-11).

\subsection{Distributive Justice at the Individual Level}

Need was rated fairest, followed by equity, then equality (Fig. 2). Thus, in accordance with Hypothesis H1.1, equity was rated fairer than equality $(\mathrm{t}(471)=3.59$, $p=0.001, \mathrm{r}=0.16)$. However, need was rated fairer than equity $(\mathrm{t}(471)=7.77$, $p<0.001, \mathrm{r}=0.34)$ and equality (RQ1.3; $\mathrm{t}(471)=11.75, p<0.001, \mathrm{r}=0.48)$, contradicting H1.2. The current situation was rated approximately as fair as the decentralized system under the equity approach $(\mathrm{t}(471)=-0.489, p>0.05, \mathrm{r}=0.02)$.

Results from the regression analysis of socio-demographic factors on the ratings as well as their differences (RQ1.4) are shown in Table 3. Respondents in the age brackets 40-49 and 60-69 rated the need approach as less fair than the reference category (the youngest respondents). The category aged 50-59 showed a tendency in the same direction. Subjects, who considered reward of contributions to be 


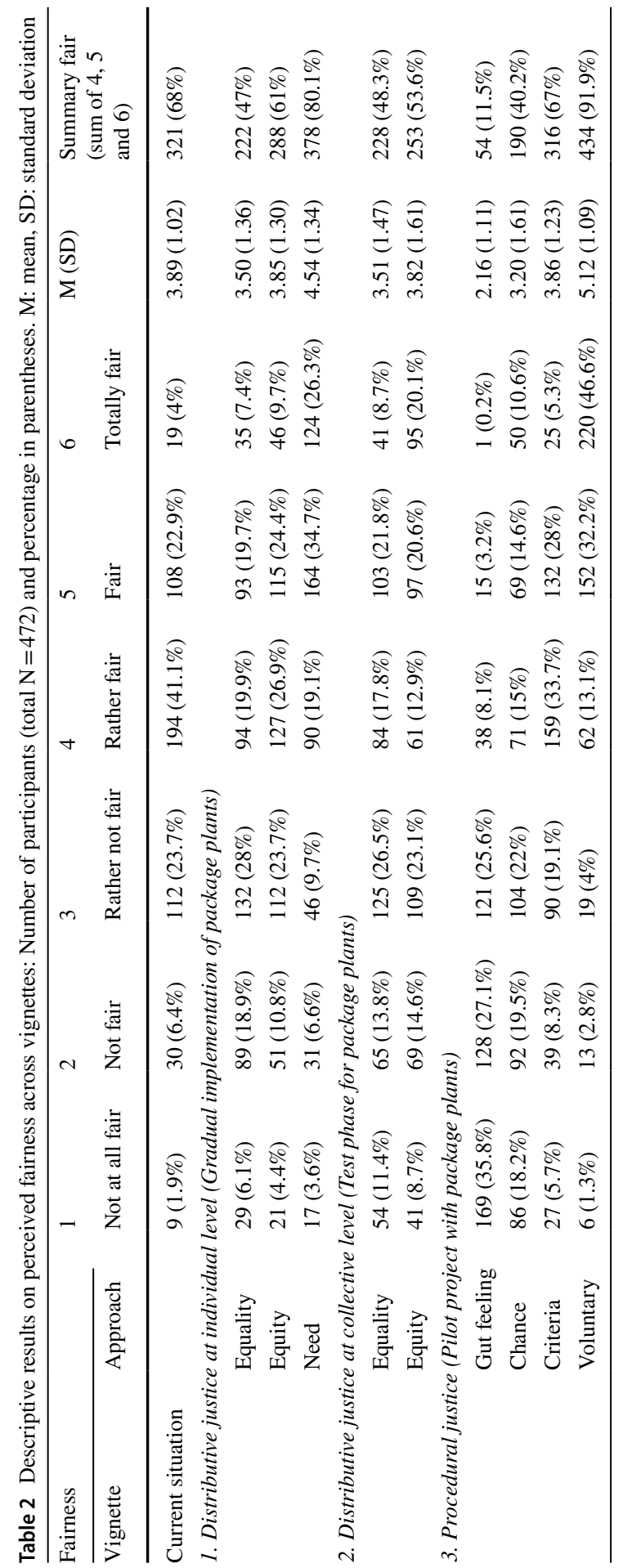



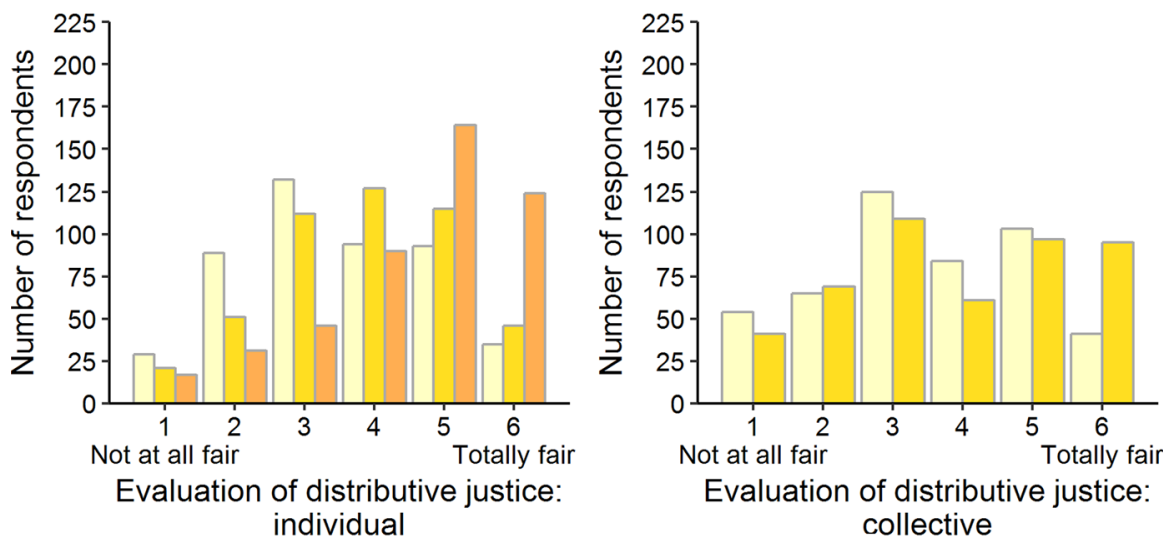

Approach $\square$ Equality $\square$ Equity

Fig. 2 Ratings of distributive justice approaches at the individual (left) and collective (right) levels

important, rated equity as fairer than others (Fig. 3). Therefore, this attitude impacts both differences between equality and equity, and between equity and need. Furthermore, respondents in most of the higher educational categories rated equality as fairer than those with secondary school education (reference category). Thus, the difference in ratings between equality and need increases significantly for higher educational categories.

However, overall significance of the regression models and their explanatory power, as indicated in adjusted $\mathrm{R}^{2}$ coefficients, were very low.

\subsection{Distributive Justice at the Collective Level}

On the collective level, two villages participate—or not—in a pilot program and receive funding for a decentralized system. Hypothesis $\mathrm{H} 2.1$ was confirmed: equity was still rated as fairer than equality, $(\mathrm{Z}=-2.70, p=0.007, \mathrm{r}=0.12)$. However, 45 participants rated one concept as totally fair, but then selected a different allocation. We excluded these respondents from the analyses of H2.2 and RQ2.3 (leaving $\mathrm{N}=427$ ).

Hypothesis $\mathrm{H} 2.2$ was confirmed: $71.7 \%(\mathrm{~N}=306)$ allocated a share higher than $50 \%$ to the participating village. A one-tailed Wilcoxon signed-rank test confirmed that the median was significantly higher than the 50:50 split (Median $=65: 35 ; \mathrm{Z}=$ $-14.24, p=0.000, \mathrm{r}=0.69$ ). The most frequent response (chosen by 23.2\%) was to give all the reward to the village participating in the test, followed by an allocation of 50\% each (19.7\%). Contrary to $\mathrm{H} 2.3$, we found no shift from equity to equality between the individual and the collective levels (Fig. 4).

When analyzing only participants who had answered both quiz questions correctly $(\mathrm{N}=284)$, the results were slightly different. The difference between equity $(\mathrm{M}=3.62$, $\mathrm{SD}=1.59)$ and equality $(\mathrm{M}=3.58, \mathrm{SD}=1.42)$, was no longer statistically significant $(\mathrm{W}=16,577, p=0.415, \mathrm{r}=-0.05)$. Although a majority of the respondents $(68.4 \%$, 


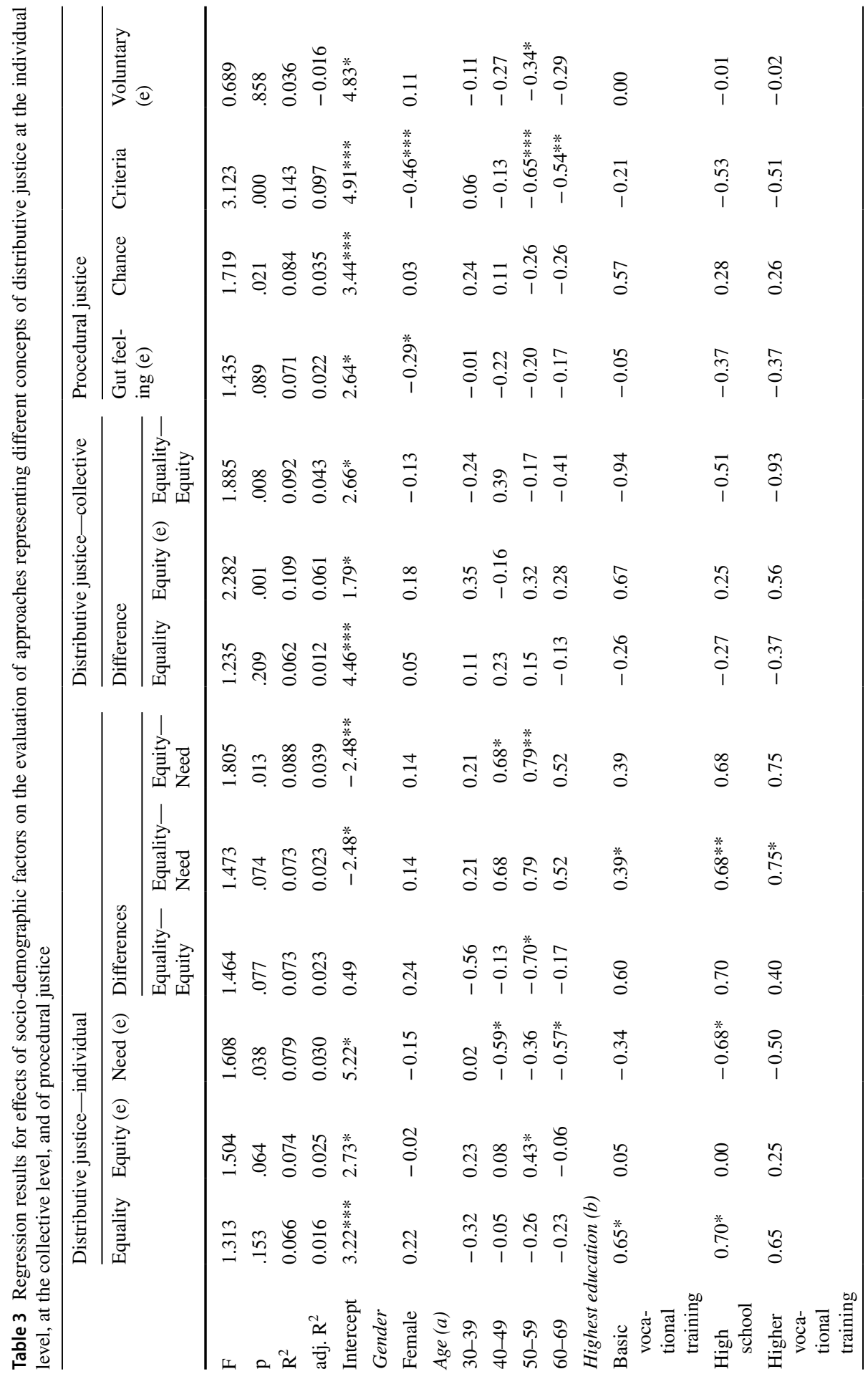




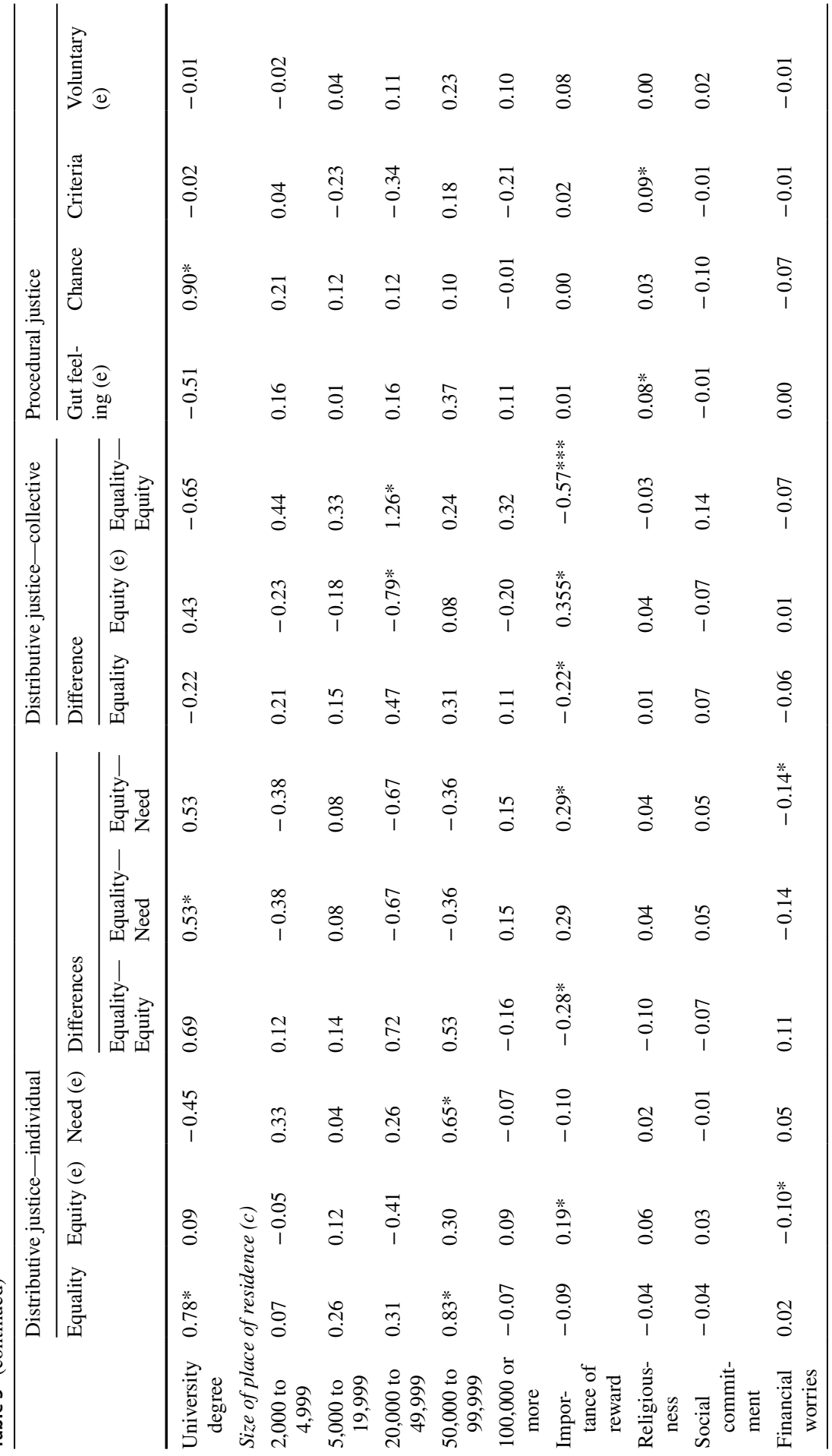




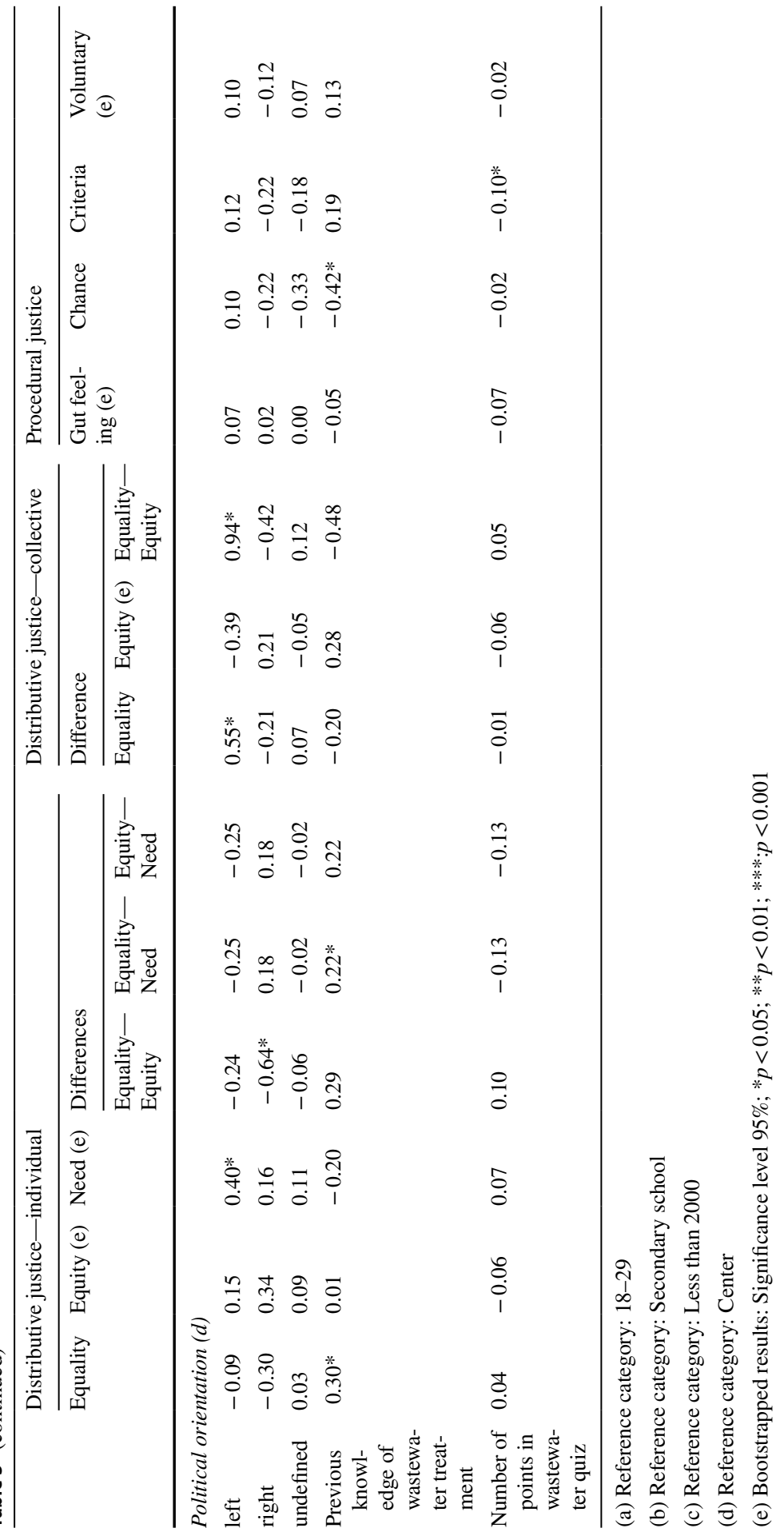




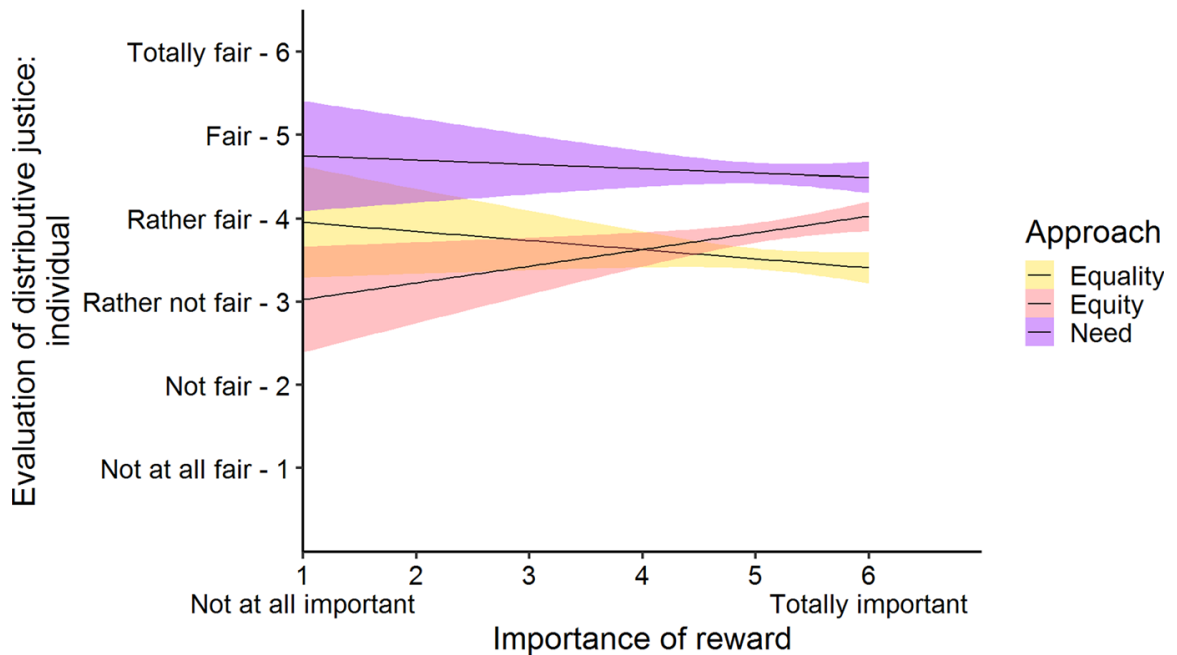

Fig. 3 Evaluation of distributive justice at the individual level on a six-point Likert scale (y-axis) depending on the perception of the importance of receiving a reward for one's contribution (x-axis)

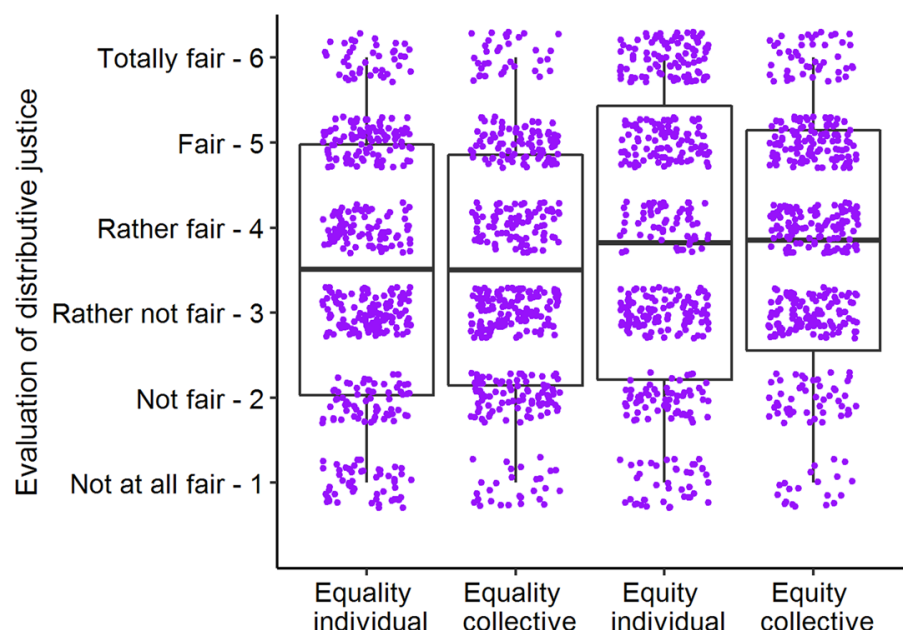

Fig. 4 Distribution of evaluations of approaches related to equity and equality at the individual and collective level on a six-point Likert scale

$\mathrm{N}=182$ ) still allocated more than $50 \%$ to the participating village (Median $=60: 40$; $p=0.000, \mathrm{r}=-0.65$ ), the most frequent response (chosen by 20.7\%) was the allocation of $50 \%$ for both villages. $17.7 \%$ allocated all the money to the participating village.

In contrast to the individual level, we did not find an effect of age. Considering reward to be important had a similar effect as before. Additionally, participants with a leftist political orientation rated equality as fairer than other participants (Table 4), leading to a bigger difference between equality and equity (Table 3 ). 
Table 4 Mean ratings and Wilcoxon rank sum tests of the fairness rating of equity and equality at the individual and collective level by political orientation

\begin{tabular}{|c|c|c|c|c|c|c|c|}
\hline \multicolumn{2}{|c|}{ Individual-collective } & \multicolumn{2}{|c|}{ Individual } & \multicolumn{2}{|c|}{ Collective } & \multicolumn{2}{|c|}{ Difference } \\
\hline & & Equality & Equity & Equality & Equity & Equality & Equity \\
\hline \multicolumn{8}{|c|}{ Political orientation } \\
\hline \multirow[t]{2}{*}{ (Means) } & Other & 3.49 & 3.85 & 3.39 & 3.93 & 0.10 & -0.08 \\
\hline & Left & 3.55 & 3.85 & 3.97 & 3.42 & -0.42 & 0.43 \\
\hline \multirow[t]{3}{*}{ Statistics } & $\mathrm{W}$ & 17,772 & 18,469 & 14,130 & 21,603 & 21,553 & 14,809 \\
\hline & $p$ & 1.000 & 1.000 & .003 & .044 & .049 & .023 \\
\hline & $\mathrm{r}$ & 0.02 & 0.01 & 0.16 & 0.13 & 0.13 & 0.14 \\
\hline
\end{tabular}

$\mathrm{W}=$ Wilcoxon rank sum test statistic (two-sided, unpaired), $p=$ significance level (Bonferroni corrected), $\mathrm{r}=$ effect size

Given that we already had to reject hypothesis H2.3, we cannot expect a strong influence of individual characteristics on differences between the levels. A regression model only reached a significance level of the overall model fit at $p<0.10$.

\subsection{Procedural Justice}

In accordance with $\mathrm{H} 3.1$, the fairness rating increased, the more criteria of procedural fairness an approach fulfilled (Fig. 5; Table 5).

To analyze RQ3.2, we regressed ratings on the individual characteristics (Table 3, columns "Procedural justice"). Women rated "Gut feeling" $\left(\mathrm{M}_{\mathrm{m}}=2.246, \mathrm{M}_{\mathrm{f}}=2.086\right)$ and "Criteria" $\left(\mathrm{M}_{\mathrm{m}}=4.061, \mathrm{M}_{\mathrm{f}}=3.668\right)$ as less fair than men. Older subjects rated "Criteria" and "Voluntary" participation as less fair than younger ones. Education had an impact on the rating of "Chance": university graduates rated this as fairer than the reference category (Secondary school). With increasing education, "Gut feeling" was rated as less fair, and "Chance" as fairer (Fig. 6). Moreover, respondents who had previous knowledge in wastewater disposal rated "Chance" as less fair than the others.

\section{Discussion}

\subsection{Distributive Justice}

\subsubsection{Evaluation of Concepts}

Our results support our hypotheses only partially. Although the ranking of equity vs. equality corresponded to our expectations, need was seen as fairer than the other two approaches. Need was rated as rather fair, fair, or totally fair by $80 \%$ of our respondents, that fraction was only $47 \%$ for equality, and $61 \%$ for equity 


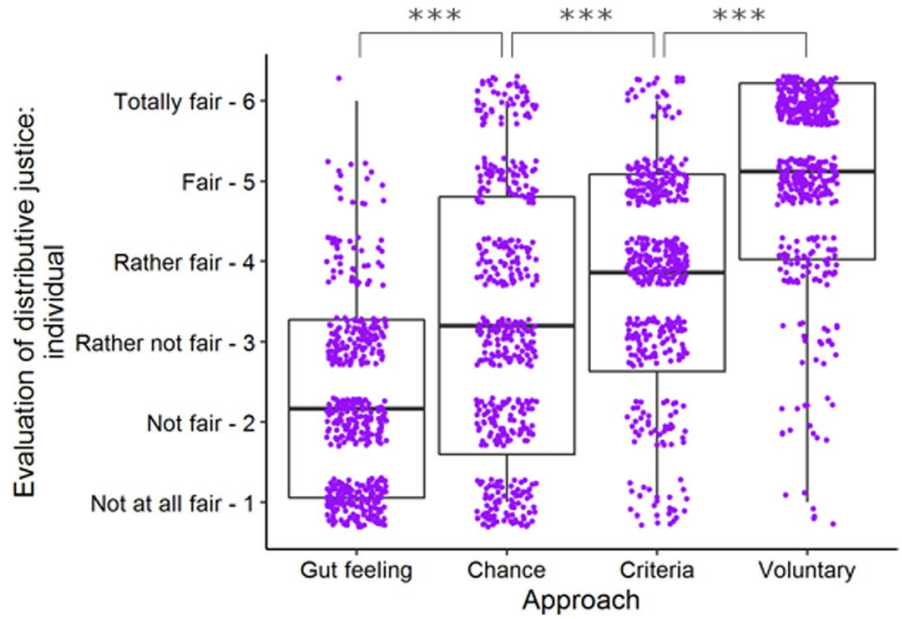

Fig. 5 Distribution of fairness ratings for approaches representing different levels of procedural justice. $(* * * p<.001)$

Table 5 Comparison of approaches of procedural justice. $\mathrm{Z}=$ test statistic of Wilcoxon signed-rank test, $p=$ significance level (Bonferroni corrected), $\mathrm{r}=$ effect size

\begin{tabular}{|c|c|c|c|c|c|c|c|c|c|c|c|}
\hline & \multirow[t]{2}{*}{ Mean } & \multirow[t]{2}{*}{ SD } & \multicolumn{3}{|c|}{ Gut feeling } & \multicolumn{3}{|l|}{ Chance } & \multicolumn{3}{|l|}{ Criteria } \\
\hline & & & $\mathrm{Z}$ & $\mathrm{p}$ & $\mathrm{r}$ & $\mathrm{Z}$ & $\mathrm{p}$ & $\mathrm{r}$ & $\mathrm{Z}$ & $\mathrm{p}$ & $\mathrm{r}$ \\
\hline Gut feeling & 2.16 & 1.11 & & & & & & & & & \\
\hline Chance & 3.20 & 1.61 & -11.31 & $<.001$ & 0.52 & & & & & & \\
\hline Criteria & 3.86 & 1.23 & -16.30 & $<.001$ & 0.75 & -7.57 & $<.001$ & 0.35 & & & \\
\hline Voluntary & 5.12 & 1.09 & -18.18 & $<.001$ & 0.84 & -14.55 & $<.001$ & 0.67 & -13.00 & $<.001$ & 0.60 \\
\hline
\end{tabular}

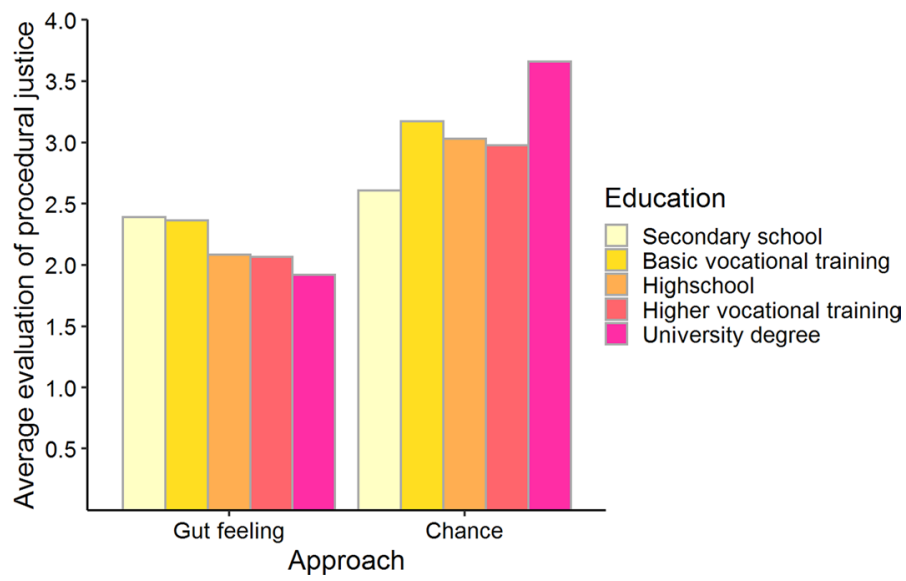

Fig. 6 Average fairness ratings of two approaches of procedural justice by education level 
(Table 2). Our results contrast literature which found that equity is considered the fairest approach in an economic context (Barber and English 2018; Deutsch 1975). However, in other contexts, literature also found a preference for need similar to our results (Steiner et al. 2006). Content analysis of key policy documents in Australia revealed that need was the dominating social justice principle for water allocation, followed by efficiency (Lukasiewicz et al. 2013). In a related study, the equity criterion "how hard the user worked and therefore deserved the water" was rated one of the least important criteria (Syme et al. 1999). Thus, it is clearly necessary to analyze fairness criteria specifically in their application context. A tentative explanation why need could be rated so highly in this context is that respondents considered installing a decentralized wastewater system as an investment that some households could not afford, rather than as a contribution that merits rewarding. If this is indeed the case, projects that promote decentralized systems might be more readily accepted. Unfortunately, our data does not allow us to verify this interpretation.

The relative rating of equality (47\% rated it as rather fair to totally fair) versus equity (61\%; Table 2) was in accordance with our hypotheses. Rewarding contributors for their effort is seen as fair, even if this results in an unequal allocation. This view is also common in the context of wastewater infrastructure planning.

However, this rating could also result from the fairness bias (Johansson-Stenman and Konow 2010; Miller 1992; Reeskens and van Oorschot 2013), which predicts that subjects prefer the principle that increases their own share. Possibly, participants viewed themselves as potential contributors. Since equity benefits the contributors, they would then prefer equity. This illustrates the difference between active and passive roles (Steiner et al. 2006) and between personal justice (affecting oneself) and third party justice (affecting someone else) found in literature (Bernerth and Walker 2012). In contrast, no such differences were found e.g., in Australian case studies on water allocation (Syme et al. 1999).

Evaluations of fairness could also be influenced by heuristics (Messick 1993). Heuristics can influence decision-making and actual behavior in situations such as resource allocations that involve fairness considerations, but heuristics can also affect the moral judgement of a situation (Sunstein 2005). For instance, allocating resources according to equality avoids the cognitive effort for measuring and comparing contributions, leading to an "equality heuristic" in resource allocation problems (Messick 1993). Except for the explicit allocation decision in vignette 2 , our survey requested ratings of the fairness of allocations presented to the subjects, who did not have to make allocation decisions themselves. Therefore, allocations according to all criteria received the same level of salience, and we consider it unlikely that this equality heuristic had a strong influence on our results.

However, our questionnaire is quite long; therefore, exhaustion of subjects might have pushed them towards using heuristics also in their fairness evaluations of alternative allocations presented to them. The effect of such heuristics is difficult to evaluate, since in contrast to studies of biases in decision-making, there is no objectively "correct" answer to which responses could be compared (Sunstein 2005). We therefore have to leave the possible impact of such heuristics as a topic for future research. 
Although we expected the difference between equity and equality to be smaller at the collective level (H2.3), our data did not support this hypothesis (Fig. 4). Possibly, the problem of free-riding was not salient to some respondents. If we consider education as a proxy for the ability to thoroughly analyze this possibility, we find limited support for this explanation: the difference between individual and collective levels in the evaluation of equity mostly increased with education. The only exception were respondents with a high school degree, for whom the difference is largest.

However, some respondents might have taken the relationship between allocation to communities and individual effects into consideration. Since the contributing village had already installed ten package plants for the test phase (financed by the government), it does not need to install as many package plants as the non-contributing village. Consequently, even an equal split would favor the contributing village. Moreover, since the actual pilot users already had a package system in place, later contributions would benefit only those inhabitants of the contributing village who had not previously installed a plant (and thus are free-riders). Some participants explicitly mentioned this imbalance in their comments.

Furthermore, analyzing the subsample of participants who answered both control questions correctly, did not result in a significant difference between equality and equity (SI-3). It seems that participants, who took more time to read and think about the vignettes, were more likely to consider the impacts on individuals. Unfortunately, it seems the vignette did not explain the individual differences resulting from allocations at the village level clearly enough. In future empirical studies, the impact of collective allocations on individuals should be explained to participants in more detail.

\subsubsection{Explanatory Factors}

The regression models we used to explain fairness perceptions mostly exhibited rather low explanatory power (Table 3). Subjects who considered it important to reward effort ranked equity consistently higher (Fig. 3). Indeed, rewarding effort could almost be seen as a proxy of the equity principle. It is also plausible that respondents with a leftist political orientation considered equality as more appropriate, especially at the collective level (Tables 3,4).

Respondents with the lowest level of education preferred the need principle even more over equality than other respondents (Table 3). This might again be interpreted as a self-serving bias (Johansson-Stenman and Konow 2010; Reeskens and van Oorschot 2013). Respondents with lower education typically also have lower income. They might benefit most from the need principle or they might better understand those who need financial support. This group was also the only one considering equality as less fair at the individual than at the collective level, while all others evaluated equality very similarly at both levels.

Interestingly, neither religiousness nor social commitment significantly influenced any ratings (Table 3). This is surprising, since we expected that 'helping the poor' can be a priority of religion (e.g., the Christian religion), and thus need should be rated as particularly fair. This contradicts results indicating a positive relationship between religion and prosocial behavior (Hoge and Yang 1994; Pichon et al. 2007; 
Saroglou et al. 2005; Shariff and Norenzayan 2007), and the impact of religiosity on preference for justice principles (Blake 2012). However, other studies found that religiosity was only associated with the willingness to help friends or family, but not unknown individuals (Saroglou et al. 2005). Moreover, self-reported religiousness was not associated with prosocial behavior (Shariff and Norenzayan 2007). Thus, our self-reported measure, which furthermore did not differentiate between religions, might not have provided the necessary level of detail to study such relationships. Similar limitations possibly also apply to our measure of social commitment.

\subsection{Procedural Justice}

\subsubsection{Evaluation of Concepts}

Our results concerning procedural justice are in accordance with expectations (Colquitt 2001; Cook and Hegtvedt 1983; Konow 2003; Thibaut and Walker 1978): the more criteria an approach fulfils, the fairer it was perceived (H3.1; Fig. 5; Table 5). Although only 64 respondents (13.6\%) exhibited the entire predicted ranking, predicted pairwise comparisons were reflected in a majority of responses (Fig. 7). While only 52\% preferred the "Chance" approach over "Gut feeling" (left bar in Fig. 7), almost 70\% preferred "Voluntary" over "Criteria" (right bar in Fig. 7). Thus, having a voice in the allocation process seems an essential element of procedural fairness. This is in line with literature, for instance, participating in decisionmaking was a significant determinant of fairness in water allocation decisions (Syme et al. 1999). In our study, an equal treatment that cannot be influenced ("Chance") was seen as hardly better than an approach which does not fulfill any criteria.

\subsubsection{Explanatory Factors}

Respondents with a university degree evaluated "Chance" and "Criteria" as significantly fairer than others. It seems plausible that respondents with some basic training in statistics are more likely to consider a random mechanism as procedurally fair. The same group rated "Gut feeling" as slightly less fair than the average, although this was only significant at the 10\%-level (Fig. 6; Table 6). Possibly, participants with a university degree are more used to decide for themselves and thus perceived decisions by another person as especially unfair.

Gender had a significant effect. "Gut feeling" and "Criteria" were perceived as less fair by women (Table 3). One possible interpretation is that women might be uneasy to delegate decisions to an authority (the mayor or scientific experts).

Finally, respondents who had previous knowledge about wastewater disposal rated "Chance" as significantly less fair than other respondents. Possibly, they have a better idea of the difficulties associated with a package plant. It thus might be clearer to them that "Chance" could select very unsuitable (e.g., elderly) residents, who are unable to maintain a package plant. 


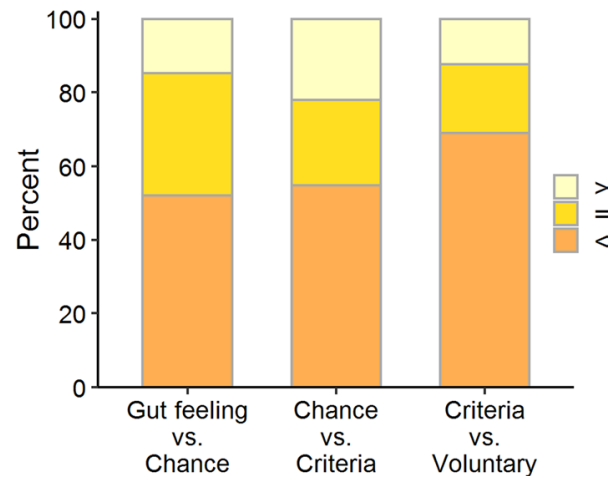

Fig. 7 Fraction of respondents who exhibited the predicted ranking (marked with "<") vs. indifference $(=)$ and opposite ranking $(>$ ) between approaches of procedural justice. Example (left bar): $52 \%$ (orange) of the respondents rated "Gut feeling" as less fair than "Chance", as it was expected in H3.1. $33 \%$ (bright yellow) rated "Gut feeling" and "Chance" as equally fair. 15\% (light yellow) rated "Gut feeling" as fairer than "Chance", which is the opposite of what we expected in H3.1

Table 6 Evaluation of different levels of procedural justice for participants with and without university degree

\begin{tabular}{llllll}
\hline & & Gut feeling & Chance & Criteria & Voluntary \\
\hline Highest education & University degree & 1.919 & 3.658 & 4.126 & 5.162 \\
(Mean) & No university degree & 2.238 & 3.061 & 3.776 & 5.108 \\
Statistics & $\mathrm{W}$ & 22,871 & 15,745 & 16,517 & 20,117 \\
& $p$ & .074 & .002 & .015 & 1.000 \\
& $\mathrm{r}$ & 0.11 & 0.16 & 0.13 & 0.00 \\
\hline
\end{tabular}

$\mathrm{W}=$ Wilcoxon rank sum test statistic (two-sided, unpaired), $p=$ significance level (Bonferroni corrected), $\mathrm{r}=$ effect size

\section{Conclusions and Future Research}

\subsection{Practical Contributions}

Especially in rural areas, it might be beneficial to replace centralized wastewater systems by more decentralized ones, even though this entails some inconvenience for end-users (Lienert and Larsen 2007, 2010). From a case study about the decision-making process in the wastewater sector, we know that the population of small rural communities considers fairness an important objective (Haag et al. 2019). A main goal of our study was to identify appropriate concepts of fairness 
in this context to ensure that solutions are acceptable to relevant stakeholders. In the Swiss direct democracy system, it is crucial to carefully prepare the introduction of innovations that directly affect citizens at the communal level, who eventually have to decide about such projects. Our survey results, representative for the German speaking part of Switzerland, thus provide policy makers and authorities with a better basis for entering a dialogue with the population and to introduce decentralized wastewater systems.

Our results lead to two main conclusions for policy makers: first, 92\% of our participants rated a decision process that includes the affected parties as rather fair, fair, or totally fair. This argues for the inclusion of citizens and is in line with earlier results (Lienert and Larsen 2007, 2010). We therefore recommend to work not only with community officials, but also to invite citizens to participate in the decision process. Literature describes different ways to involve the community: Public hearings (Fiorino 1990) are a loosely structured form involving only interested citizens who take the initiative themselves. A public survey provides a broader range of opinions (Fiorino 1990). Deliberative microcosm (Meadowcroft 2004) involves a selected group of representative citizens, who debate, judge, and propose solutions. Causal mapping workshops (Kaur and Carreras 2018) can be specifically designed to follow principles of procedural fairness. However, we wish to emphasize that the study took place in Switzerland that has a strong tradition of public decision-making. Participation in the decision process might therefore be less decisive in other countries.

Concerning distributive justice, we found that contrary to our expectations, need was perceived as rather fair, fair, or totally fair by $80 \%$ of the respondents. One possible interpretation is that respondents did not view e.g., participation in a pilot program as a contribution that deserves rewarding, but rather as an investment that not everyone can afford. If the installation of a package plant is indeed seen only as minor nuisance, resistance against introducing such systems might be low. This is, however, a rather tentative argument since answering a hypothetical survey question is quite different from actually installing such a system. At least, it seems that the general population might not worry extensively about this move.

Interestingly, the participants had a relatively neutral opinion concerning the fairness of the current situation (64\% of the ratings were in the two middle classes; Table 2). Thus, some ways to introduce a decentralized system are judged as fair as the current situation.

The results also indicated a clear ranking between equity and equality at both the individual and the collective level. After need, our respondents ranked rewarding contributions next. Decision makers should consider this, when trying to motivate citizens to participate in pilot or test projects. In our examples, the rewards were always monetary. Other forms of reward (e.g., an official thank you or other appreciation) might work, too. Future studies should investigate, what kind of reward stakeholders appreciate the most and how high it should be. 


\subsection{Scientific Contribution and Future Research}

Our study contributes to the growing body of literature that tests fairness principles in different contexts such as social security systems (Reeskens and van Oorschot 2013), job design (Romaine and Schmidt 2009), sports (Mahony et al. 2010), or service provisions such as allocating water resources (Lukasiewicz et al. 2013; Syme et al. 1999), and childcare (Eek et al. 1998). Different fairness criteria are perceived as just in different contexts (Otto et al. 2011). By identifying the fairness criteria that citizens consider relevant in the specific context of wastewater treatment, we firstly follow a pragmatic approach to support decision makers to develop solutions that find broad support in the general population. Informing decision makers about the values of those affected by major changes also fulfills a normative goal, since in a democratic system, these values are the legitimate basis for decision-making on public issues. Empirical research such as ours can thus also contribute to normative research by providing insights about the acceptability of normatively defined solutions (Miller 1992).

Our results are necessarily limited to the described wastewater planning decision problem in its institutional (Swiss) context. However, we believe that our study provides some more general insights such as the relationship between the individual and collective levels. Most respondents rated fairness criteria quite similar at both levels. Our exploratory idea that the equity principle could be perceived as less fair at the collective level was not confirmed in this study. However, since analysis of the open questions revealed that only a fraction of the respondents actually considered the individual impact of allocations made to groups, there is obviously a need for more research on this topic.

We only found weak influences of individual characteristics on the evaluation of fairness criteria. Overall, most regression models could only explain a very small part of the variance in evaluations. This suggests that other factors such as personality might influence perceptions of fairness. In fact, empirical research indicates that the personality dimension of agreeableness positively affects perceptions of procedural and distributive justice, while neuroticism has a negative effect (Bernerth et al. 2006; Junqi et al. 2009; Törnroos et al. 2019). However, the explanatory power of these models is very similar to ours, typically adjusted $\mathrm{R}^{2}$ values are below 0.1 , and often below 0.05 . Thus, including personality factors in our models would have lengthened the survey considerably, without adding much explanatory power.

The low impact of individual factors again highlights the importance of the specific context on fairness perceptions: in order to provide advice to decision makers, it is necessary to elicit fairness perceptions in the exact application context. Our study has done this for a context that requires significant public investments and a considerable shift in responsibilities in the near future, and where it is therefore essential to know which approaches relevant stakeholders would consider as fair.

Supplementary Information The online version contains supplementary material available at https://doi. org/10.1007/s10726-021-09725-2.

Acknowledgements This work was financed by Eawag: Swiss Federal Institute of Aquatic Science and Technology. We thank Philipp Beutler for supporting technical and policy questions, everyone who tested 
our survey and gave valuable feedback, all respondents for their time and providing these important data and the two anonymous reviewers for their thoughtful comments that greatly helped to improve this paper.

Funding Open Access funding provided by Lib4RI - Library for the Research Institutes within the ETH Domain: Eawag, Empa, PSI and WSL.

Open Access This article is licensed under a Creative Commons Attribution 4.0 International License, which permits use, sharing, adaptation, distribution and reproduction in any medium or format, as long as you give appropriate credit to the original author(s) and the source, provide a link to the Creative Commons licence, and indicate if changes were made. The images or other third party material in this article are included in the article's Creative Commons licence, unless indicated otherwise in a credit line to the material. If material is not included in the article's Creative Commons licence and your intended use is not permitted by statutory regulation or exceeds the permitted use, you will need to obtain permission directly from the copyright holder. To view a copy of this licence, visit http://creativecommons.org/licen ses/by/4.0/.

\section{References}

Ahmed AM, Salas O (2011) Implicit influences of Christian religious representations on dictator and prisoner's dilemma game decisions. J Socio-Econ 43:242-246. https://doi.org/10.1016/j.socec .2010.12.013

Barber BS, English W (2018) The origin of wealth matters: Equity norms trump equality norms in the ultimatum game with earned endowments. J Econ Behav Organ 158:33-43. https://doi. org/10.1016/j.jebo.2018.11.008

Bellemare C, Kröger S, van Soest A (2011) Preferences, intentions, and expectation violations: a largescale experiment with a representative subject pool. J Econ Behav Organ 78:349-365. https://doi. org/10.1016/j.jebo.2011.01.019

Bernerth J, Walker HJ (2012) Reexamining the workplace justice to outcome relationship: Does frame of reference matter? J Manage Stud 49:945-969. https://doi.org/10.1111/j.1467-6486.2010.00977.x

Bernerth JB, Feild HS, Giles WF, Cole MS (2006) Perceived fairness in employee selection: the role of applicant personality. J Bus Psychol 20:545-563. https://doi.org/10.1007/s10869-005-9004-3

Besley JC (2010) Public engagement and the impact of fairness perceptions on decision favorability and acceptance. Sci Commun 32:256-280. https://doi.org/10.1177/1075547009358624

Beutler P, Larsen TA, Maurer M, Staufer P, Würsten M, Lienert J (2020) Zukünftige Abwasserentsorgung im ländlichen Raum - Fallstudie 2. Abschlussbericht für die Gemeinde. (Future wastewater management in rural regions - case study 2. Final report for the municipality). Eawag: Swiss Federal Institute of Aquatic Science and Technology, Dübendorf, Switzerland. https://www.dora.lib4ri.ch/eawag/ islandora/object/eawag:19949. Accessed 12.01.2021.

Bies RJ (1987) The predicament of injustice: The management of moral outrage. Research in organizational behavior 9:289-319

Blake W (2012) God save this honorable court: Religion as a source of judicial policy preferences. Political Res Quarterly 65:814-826. https://doi.org/10.1177/1065912911421015

Cappelen AW, Hole AD, Sorensen E, Tungodden B (2007) The pluralism of fairness ideals: an experimental approach. Am Econ Rev 97:818-827. https://doi.org/10.1257/aer.97.3.818

Clayton S (2000) New ways of thinking about environmentalism: Models of justice in the environmental debate. J Soc Issues 56:459-474. https://doi.org/10.1111/0022-4537.00178

Cohn ES, White SO, Sanders J (2000) Distributive and procedural justice in seven nations. Law Hum Behav 24:553-579

Colquitt JA (2001) On the dimensionality of organizational justice: A construct validation of a measure. J Appl Psychol 86:386-400. https://doi.org/10.1037//0021-9010.86.3.386

Conlon DE, Porter COLH, McLean Parks J (2004) The fairness of decision rules. J Manage 30:329-349. https://doi.org/10.1016/j.jm.2003.04.001

Cook KS, Hegtvedt KA (1983) Distributive justice, equity, and equality. Ann Rev Sociol 9:217-241. https://doi.org/10.1146/annurev.so.09.080183.001245 
Cook RD, Weisberg S (1982) Residuals and influence in regression. Chapman and Hall, New York. https ://doi.org/10.1002/bimj.4710270110

Cropanzano R, Molina A (2015) Organizational justice. In: Wright JD (ed) International Encyclopedia of the Social and Behavioral Sciences, 2nd edn. Elsevier, Oxford, pp 379-384. https://doi.org/10.1016/ B978-0-08-097086-8.22033-3

Decety J, Cowel JM, Lee K, Mahasneh R, Malcolm-Smith S, Selcuk B, Zhou XY (2015) The negative association between religiousness and children's altruism across the world. Curr Biol 25:29512955. https://doi.org/10.1016/j.cub.2015.09.056

Delton AW, Cosmides L, Guemo M, Robertson TE, Tooby J (2012) The psychosemantics of free riding: dissecting the architecture of a moral concept. J Pers Soc Psychol 102:1252. https://doi.org/10.1037/ a0027026

Deutsch M (1975) Equity, equality, and need - What determines which value will be used as basis of distributive justice. J Soc Issues 31:137-149. https://doi.org/10.1111/j.1540-4560.1975.tb01000.x

Eek D, Biel A, Gärling T (1998) The effect of distributive justice on willingness to pay for municipality child care: an extension of the GEF hypothesis. Social Justice Res 11:121-142. https://doi. org/10.1023/A:1023203320261

Eggimann S, Truffer B, Maurer M (2015) To connect or not to connect? Modelling the optimal degree of centralisation for wastewater infrastructures. Water Res 84:218-231. https://doi.org/10.1016/j.watre S.2015.07.004

Farrelly M, Brown R (2011) Rethinking urban water management: experimentation as a way forward? Global Environ Change 21:721-732. https://doi.org/10.1016/j.gloenvcha.2011.01.007

Fehr E, Schmidt KM (1999) A theory of fairness, competition, and cooperation. Quart J Econ 114:817868. https://doi.org/10.1162/003355399556151

Field A, Miles J, Field Z (2012) Discovering statistics using R. Sage publications, Thousand Oaks

Fiorino DJ (1990) Citizen participation and environmental risk: A survey of institutional mechanisms. Sci Technol Human Values 15:226-243. https://doi.org/10.1177/016224399001500204

Frey BS, Oberholzer-Gee F (1996) Fair siting procedures: An empirical analysis of their importance and characteristics. J Policy Anal Manage 15:353-376. https://doi.org/10.1002/(sici)1520-6688(19962 2) $15: 3 \% 3 c 353::$ Aid-pam $2 \% 3 \mathrm{e} 3.0 . \mathrm{Co} ; 2-\mathrm{h}$

Gaertner W, Schokkaert E (2012) Empirical social choice: questionnaire-experimental studies on distributive justice. Cambridge University Press, Cambridge

Gao Y (2009) A study of fairness judgments in China, Switzerland and Canada: Do culture, being a student, and gender matter? Judgment Decision Making 4:214-226

Gleick PH (2003) Global freshwater resources: soft-path solutions for the 21 st century. Science 302:1524-1528. https://doi.org/10.1126/science.1089967

Haag F, Zürcher S, Lienert J (2019) Enhancing the elicitation of diverse decision objectives for public planning. Eur J Oper Res 279:912-928. https://doi.org/10.1016/j.jenvman.2019.109652

Harris-Lovett SR, Binz C, Sedlak DL, Kiparsky M, Truffer B (2015) Beyond user acceptance: a legitimacy framework for potable water reuse in California. Environ Sci Technol 49:7552-7561. https:// doi.org/10.1021/acs.est.5b00504

Hegtvedt KA (2005) Doing justice to the group: Examining the roles of the group in justice research. Ann Rev Sociol 31:25-45

Heneman RL, von Hippel C (1995) Balancing group and individual rewards: Rewarding individual contributions to the team. Compensat Benefits Rev 27:63-68

Herrero C, Moreno-Ternero JD, Ponti G (2010) On the adjudication of conflicting claims: an experimental study. Soc Choice Welfare 34:145-179. https://doi.org/10.1007/s00355-009-0398-0

Heuer L, Penrod S, Kattan A (2007) The role of societal benefits and fairness concerns among decision makers and decision recipients. Law Hum Behav 31:573-610

Hoffmann S et al (2020) A research agenda for the future of urban water management: Exploring the potential of nongrid, small-grid, and hybrid solutions. Environ Sci Technol 54:5312-5322. https:// doi.org/10.1021/acs.est.9b05222

Hoge DR, Yang F (1994) Determinants of religious giving in American denominations: data from two nationwide surveys. Rev Religious Res 36:123-148

Hurlimann A, Dolnicar S (2010) When public opposition defeats alternative water projects-the case of Toowoomba Australia. Water Res 44:287-297. https://doi.org/10.1016/j.watres.2009.09.020

Isaksson A-S, Lindskog A (2009) Preferences for redistribution-a country comparison of fairness judgements. J Econ Behav Organ 72:884-902. https://doi.org/10.1016/j.jebo.2009.08.006 
Jiang YS, Bachner-Melman R, Chew SH, Ebstein RP (2015) Dopamine D4 receptor gene and religious affiliation correlate with dictator game altruism in males and not females: Evidence for gender-sensitive gene x culture interaction. Front Neurosci 9:10. https://doi.org/10.3389/fnins.2015.00338

Johansson-Stenman O, Konow J (2010) Fair air: Distributive justice and environmental economics. Environ Resource Econ 46:147-166. https://doi.org/10.1007/s10640-010-9356-7

Jungeilges JA, Theisen T (2008) A comparative study of equity judgements in Lithuania and Norway. J Socio-Econ 37:1090-1118. https://doi.org/10.1016/j.socec.2007.04.002

Junqi S, Han L, Lei W, Mo W (2009) Linking the big five personality constructs to organizational justice. Social Behav Personal Int J 37:209-222. https://doi.org/10.2224/sbp.2009.37.2.209

Kaur P, Carreras AL (2018) Capturing the participants' voice: using causal mapping supported by group decision software to enhance procedural justice. Paper presented at the 18 th International Conference on Group Decision and Negotiation, GDN 2018

Kervinio Y (2016) Assessing the fairness of public policies: proposal for an approach with an illustration for the location of locally undesirable land uses. Doctoral Thesis, Toulouse School of Economics

Koenig LB, McGue M, Krueger RF, Bouchard TJ (2007) Religiousness, antisocial behavior, and altruism: genetic and environmental mediation. J Pers 75:265-290. https://doi.org/10.111 1/j.1467-6494.2007.00439.x

Konow J (2003) Which is the fairest one of all? A positive analysis of justice theories. J Econ Literat 41:1188-1239. https://doi.org/10.1257/002205103771800013

Larsen TA, Alder AC, Eggen RI, Maurer M, Lienert J (2009) Source separation: will we see a paradigm shift in wastewater handling? Environ Sci Technol 43:6121-6125. https://doi.org/10.1021/es803 $001 \mathrm{r}$

Larsen TA, Hoffmann S, Lüthi C, Truffer B, Maurer M (2016) Emerging solutions to the water challenges of an urbanizing world. Science 352:928-933. https://doi.org/10.1126/science.aad8641

Larsen TA, Udert KM, Lienert J (2013) Source separation and decentralization for wastewater management. IWA Publishing, London. https://doi.org/10.2166/9781780401072

Leventhal GS, Karuza J, Fry WR (1980) Beyond fairness: A theory of allocation preferences. Justice Social Interact 3:167-218

Li A, Cropanzano R (2009) Fairness at the group level: justice climate and intraunit justice climate. J Manage 35:564-599. https://doi.org/10.1177/0149206308330557

Libralato G, Ghirardini AV, Avezzù F (2012) To centralise or to decentralise: an overview of the most recent trends in wastewater treatment management. J Environ Manage 94:61-68. https://doi. org/10.1016/j.jenvman.2011.07.010

Lienert J, Larsen TA (2007) Pilot projects in bathrooms: a new challenge for wastewater professionals. Water Practice Technol 2:2007057. https://doi.org/10.2166/wpt.2007.057

Lienert J, Larsen TA (2010) High acceptance of urine source separation in seven European countries: a review. Environ Sci Technol 44:556-566. https://doi.org/10.1021/es9028765

Lukasiewicz A, Bowmer K, Syme GJ, Davidson P (2013) Assessing government intentions for Australian water reform using a social justice framework. Soc Nat Resour 26:1314-1329. https://doi. org/10.1080/08941920.2013.791903

Mahony DF, Hums MA, Andrew DPS, Dittmore SW (2010) Organizational justice in sport. Sport Manage Rev 13:91-105. https://doi.org/10.1016/j.smr.2009.10.002

Mannix EA, Neale MA, Northcraft GB (1995) Equity, equality, or need? The effects of organizational culture on the allocation of benefits and burdens. Organ Behav Hum Decis Process 63:276-286. https://doi.org/10.1006/obhd.1995.1079

McConville JR, Künzle R, Messmer U, Udert KM, Larsen TA (2014) Decision support for redesigning wastewater treatment technologies. Environ Sci Technol 48:12238-12246. https://doi.org/10.1021/ es501854x

Meadowcroft J (2004) Participation and sustainable development: modes of citizen, community and organisational involvement. Governance Sustain Develop Challenge Adapt Funct. https://doi. org/10.4337/9781845421700.00014

Messick DM (1993) Equality as a decision heuristic. Psychol Perspect Justice Theory Appl, pp. 11-31

Miller D (1992) Distributive justice: what the people think. Ethics 102:555-593

Miller L, Ubeda P (2012) Are women more sensitive to the decision-making context? J Econ Behav Organ 83:98-104. https://doi.org/10.1016/j.jebo.2011.06.014

Mossholder KW, Bennett N, Martin CL (1998) A multilevel analysis of procedural justice context. J Organiz Behav 19:131-141. https://doi.org/10.1002/(sici)1099-1379(199803)19:2\%3c131::Aidjob878\%3e3.0.Co;2-p 
Neal MJ, Lukasiewicz A, Syme GJ (2014) Why justice matters in water governance: Some ideas for a 'water justice framework.' Water Policy 16:1-18. https://doi.org/10.2166/wp.2014.109

OECD (2015) Water and cities: ensuring sustainable futures. OECD Publishing, Paris, OECD Studies on Water. https://doi.org/10.1787/9789264230149-en

Otto K, Baumert A, Bobocel DR (2011) Cross-cultural preferences for distributive justice principles: resource type and uncertainty management. Social Justice Res 24:255-277. https://doi.org/10.1007/ s11211-011-0135-6

Pichon I, Boccato G, Saroglou V (2007) Nonconscious influences of religion on prosociality: a priming study. Europ J Soc Psychol 37:1032-1045. https://doi.org/10.1002/ejsp.416

Pratto F, Tatar DG, Conway-Lanz S (1999) Who gets what and why: determinants of social allocations. Political Psychol 20:127-150. https://doi.org/10.1111/0162-895X.00139

R Core Team (2017) R: a language and environment for statistical computing. R Foundation for Statistical Computing, Vienna

Reeskens T, van Oorschot W (2013) Equity, equality, or need? A study of popular preferences for welfare redistribution principles across 24 European countries. J Europ Public Policy 20:1174-1195. https:// doi.org/10.1080/13501763.2012.752064

Respondi (2018). www.respondi.com. Accessed July 25, 2018

Romaine J, Schmidt AB (2009) Resolving conflicts over employee work schedules: what determines perceptions of fairness? Int J Conflict Manage 20:60-81. https://doi.org/10.1108/10444060910931611

Saroglou V, Pichon I, Trompette L, Verschueren M, Dernelle R (2005) Prosocial behavior and religion: new evidence based on projective measures and peer ratings. J Sci Study Religion 44:323-348

Schokkaert E, Overlaet B (1989) Moral intuitions and economic models of distributive justice. Soc Choice Welfare 6:19-31

Schuwirth N, Reichert P, Lienert J (2012) Methodological aspects of multi-criteria decision analysis for policy support: a case study on pharmaceutical removal from hospital wastewater. Eur J Oper Res 220:472-483. https://doi.org/10.1016/j.ejor.2012.01.055

Shariff AF, Norenzayan A (2007) God is watching you: Priming God concepts increases prosocial behavior in an anonymous economic game. Psychol Sci 18:803-809

Singh NK, Kazmi A, Starkl M (2015) A review on full-scale decentralized wastewater treatment systems: techno-economical approach. Water Sci Technol 71:468-478. https://doi.org/10.2166/wst.2014.413

Steiner DD, Trahan WA, Haptonstahl DE, Fointiat V (2006) The justice of equity, equality, and need in reward distributions: a comparison of French and American respondents. Revue Int Psychol Sociale 19:49-74

Sunstein CR (2005) Moral heuristics. Behav Brain Sci 28:531-541. https://doi.org/10.1017/S0140525X0 5000099

Syme GJ, Nancarrow BE, McCreddin JA (1999) Defining the components of fairness in the allocation of water to environmental and human uses. J Environ Manage 57:51-70. https://doi.org/10.1006/ jema.1999.0282

Tabachnick BG, Fidell LS (2007) Using multivariate statistics. Allyn \& Bacon/ Pearson Education US

Thibaut J, Walker L (1978) A theory of procedure. California Law Review 66:541. https://doi. org/10.15779/Z38WX8J

Törnroos M et al (2019) Personality traits and perceptions of organisational justice. Int J Psychol 54:414422. https://doi.org/10.1002/ijop. 12472

Tyler TR (1989) The psychology of procedural justice: a test of the group-value model. J Pers Soc Psychol 57:830. https://doi.org/10.1037/0022-3514.57.5.830

Welsh NA (2004) Perceptions of fairness in negotiations. Marquette Law Rev 87:753-767

Whitman DS, Caleo S, Carpenter NC, Horner MT, Bernerth JB (2012) Fairness at the collective level: a meta-analytic examination of the consequences and boundary conditions of organizational justice climate. J Appl Psychol 97:776-791

Publisher's Note Springer Nature remains neutral with regard to jurisdictional claims in published maps and institutional affiliations. 


\section{Authors and Affiliations}

\section{Sara Schmid ${ }^{1} \cdot$ Rudolf Vetschera $^{2} \cdot$ Judit Lienert ${ }^{1}$}

Sara Schmid

sara.schmid@eawag.ch

Rudolf Vetschera

rudolf.vetschera@univie.ac.at

1 Department of Environmental Social Sciences (ESS), Eawag: Swiss Federal Institute of Aquatic Science and Technology, Überlandstrasse 133, 8600 Dübendorf, Switzerland

2 Department of Business Decisions and Analytics, University of Vienna, Oskar-Morgenstern-Platz 1, 1090 Vienna, Austria 